\title{
Poemas de Eugenio Montale (1896-1981)***
}

\author{
Tradução de
}

\author{
Maria Eneida Victor Farias
}

* MONTALE, Eugenio. In: The Penguin Book of Italian Verse. Baltimore, Maryland, Penguin Books, 1966.

**: «Estou aqui porque escrevi poesias, um produto absolutamente inútil, mas quase nunca nocivo. Este é um de seus titulos de nobreza» - afirmou Eugenio Montale, na Academia Sueca, ao receber o Prêmio Nobel de Literatura, em 1975. Era então considerado um dos três grandes poetas italianos contemporâneos, junto com Ungaretti e Quasimodo.

Nasceu em Gênova, em 1896 e faleceu em Milão, a 15 de setembro de 1981. Montale é um poeta hermético; exprime-se em versos secos, limpos, quase duros. E considerado o poeta do desespero, do pessimismo. Mas a sua poesia reflete o seu tempo, sua vida, sua época. « a soma dos fatos cotidianos» - como disse seu biógrafo Giulio Nascimbeni. Escreveu OSSI DI SEPPIA (1925), LA CASA DEI DOGANIERI (1932), LE OCCASTONI (1939), FINISTERRE (1943), LA BUFERA E ALTRO (1956), etc.

Ao receber a notícia de que lhe havia sido atribuído o Prêmio Nobel de Literatura, comentou com os amigos:

- «Na vida triunfam tantos imbecis. Não gostaria de ser um deles». 
VENTO SULLA MEZZALUNA

Il grande ponte non portava a te. T'avrei raggiunta anche navigando nelle chiaviche, a un tuo comando. Ma già le forze, col sole sui cristalli delle verande, andavano stremandosi.

L'uomo che predicava sul Crescente mi chiese "Sai dov'è Dio?" Lo sapevo e glielo dissi. Scosse il capo. Sparve nel turbine che prese uomini e case e li sollevò in alto, sulla pece.

Edimburgo. 1948 
VENTO NO CRESCENTE

A grande ponte não levava a ti. Ter-te-ia alcançado mesmo navegando nas cloacas, a um teu comando. Mas já as forças, com o sol nos cristais das varandas, iam-se apagando.

O homem que pregava no Crescente me perguntou: "Sabes onde está Deus?" Eu sabia e lhe disse. Balançou a cabeça. Desapareceu no turbilhão que levou homens e casas e os ergueu para o alto, sobre o breu. Edimburgo. 1948 
Anche una piuma che vola può disegnare

la tua figura, o il raggio che gioca a rimpiattino

tra i mobili, il rimando dello specchio

di un bambino, dai tetti. Sul giro delle mura

strascichi di vapore prolungano le guglie

dei pioppi e giù sul trespolo s'arruffa il pappagallo dell'arrotino. Poi la notte afosa

sulla piazzola, e i passi, e sempre questa dura

fatica di affondare per risorgere eguali

da secoli, o da istanti, d'incubi che non possono

ritrovare la luce dei tuoi occhi nell'antro

incandescente; e ancora le stesse grida e i lunghi

pianti sulla veranda

se rimbomba improvviso il colpo che t'arrossa

la gola e schianta l'ali o perigliosa

annunziatrice dell'alba

e si destano i chiostri e gli ospedali

a un lacerio di trombe... 


\section{DIA E NOITE}

Mesmo uma pluma que voa pode desenhar

a tua figura, ou o raio que brinca de esconde-esconde entre os móveis, o reflexo do espelho de um menino, dos tetos. Sobre o círculo dos muros listrados de vapor prolongam-se as agulhas dos álamos e em baixo sobre o cavalete eriça-se o papagaio do amolador. Depois a noite sufocante na pracinha, e os passos, e sempre esta dura fadiga de submergir para ressurgir iguais por séculos, ou por instantes, de pesadelos que não podem reencontrar a luz dos teus olhos no antro incandescente; e ainda os mesmos gritos e os longos prantos na varanda

se ressoa improviso o golpe que te avermelha

a garganta e arranca as asas oh perigosa anunciadora da aurora

e despertam-se os claustros e os hospitais

a um lacerar-se de trompas... 
MOTTETTO

Lo sai: debbo riperderti e non posso.

Come un tiro aggiustato mi sommuove ogni opera, ogni grido e anche lo spiro salino che straripa

dai moli e fa l'oscura primavera di Sottoripa.

Paese di ferrame e alberature a selva nella polvere del vespro. Un ronzio lungo viene dall'aperto, strazia com'unghia ai vetri. Cerco il segno smarrito, il pegno solo ch'ebbi in grazia da te.

E l'inferno è certo. 


\section{MOTE}

Tu sabes: devo perder-te outra vez e não posso.

Como um tiro ajustado me agita

cada obra, cada grito e mesmo o respiro

salino que transborda

dos molhes e faz a obscura primavera

de Sottoripa.

Cidade de sucata e mastreação

de selva na poeira do fim da tarde.

Um zunido longo vem do aberto,

dilacera como unha nos vidros. Procuro o sinal

perdido, único penhor de amor que tive

de ti.

E o inferno é certo. 